\title{
Impedance and Resistance of Carbon Ink during Cure
}

\begin{abstract}
Purpose - The resistivity of cured conductive paste films is dependent on a wide range of process parameters. An early indication of the resistivity that is likely to result following curing can enable these parameters to be optimised and therefore improve product quality. This paper reports on the use of alternating current $(A C)$ impedance measurement techniques on curing printed paste films, as a means of assessing the resistivity likely to be attained following the curing process.

Design/methodology/approach - Impedance measurements (100 Hz to $1 \mathrm{MHz}$ ) were performed on curing conductive carbon paste films printed on polyethylene terephthalate (PET) substrates, during convective heat curing. A jig was designed to incorporate the test structure in a convection oven, such that the structure impedance could be investigated during cure.

Findings - The initial impedance was found to decrease with increasing measurement frequency. As the paste films cured, the impedance magnitude across the $100 \mathrm{~Hz}$ to $1 \mathrm{MHz}$ range converged with the $D C$ resistance value. For a given paste, the ratio of initial $A C$ impedance at $1 \mathrm{MHz}$ to final cured resistance was found to be consistent, thus giving a method where final conductivity can be estimated before cure.

Originality/value - Data from printed paste resistance measurements is required to ensure the optimal conductivity of printed devices. However, after the printed structures are fabricated and cured, it is too late to optimise process parameters, leading to significant wastage. AC Impedance measurement can give an indication of the final cured resistivity whilst the structure is freshly printed and still in its curing phase, enabling the printing process parameters to be adjusted to improve the resistivity of subsequently printed devices. Measuring AC impedance of printed paste structures in a production environment can therefore improve output.
\end{abstract}

Keywords Impedance, Curing, Resistance, Printed electronics, Carbon paste.

Paper type Research paper

\section{Introduction}

Conductive paste consists of two primary components, namely a conductive particulate and a second phase known as the 'vehicle'. The particulate provides electrical conductivity, whilst the vehicle binds the particulate into a fluid phase and confers adhesive properties that enable the paste deposits to adhere to the substrate (Derby, Reis 2003). There are different paste deposition techniques such as inkjet (Cummins, Desmulliez 2012), screen-printing (Jewell, Hamblyn et al. 2013), and lithography (Evans, Harrey et al. 2001). In this research, screen printing was used to deposit a carbon-loaded paste, onto pre-printed electrodes, forming a test structure on polyethylene terephthalate (PET) substrates. The purpose of the paste vehicle is to enable the chosen printing process to deliver the conductive particles to the intended area and form the desired structure. Once the conductive paste has been deposited, the paste vehicle needs to be cured to create particle to particle contact in excess of the percolation threshold and thus achieve electrical conductivity in the printed structure. The paste vehicle normally contains a volatile solvent that evaporates and a resin that cures through oxidative cross-linking. Both curing processes are aided by the application of heat.

Significant DC current will only pass through the printed conductive track once continuous particle to particle contact between measuring electrodes has been established. Where ohmic heating is employed, several minutes of air drying is usually necessary to create an initial level of conductance prior to application of the curing current (Roberson, Wicker et al. 2012). 
Previous research on printed paste film has focused on cured printed electronics (Salmeron, Torres et al. 2012, Lian, Li et al. 2010, Kim, Kim et al. 2010, Merilampi, Bjorninen et al. 2010) and little research (Felba 2011) has been conducted during the curing stage. Conventional characterisation methods of cured conductive pastes are based on DC resistance measurement. Meanwhile AC measurements were used to characterise cured printed electronics (Makinen, Sillanpaa et al. 2009, Pynttäri, Makinen et al. 2010).

Impedance spectroscopy is a widely used measurement technique in other fields; including conductive adhesive joints (Mach, Kolár 2009), fuel cells (Yuan, Wang et al. 2007), corrosion measurement (Foyet, Wu et al. 2009) and a wide range of other applications (Familiant, Corzine et al. 2005). Impedance measurement provides information regarding the resistive and reactive component of the system. Reactive components are due to the capacitance between the (initially isolated) conductive particles and inductive properties of the printed structure. The curing process involves the evaporation of solvents and the polymerization of the resin component of the paste vehicle. As these processes occur, more particle to particle networks are formed, causing the resistance to decrease. The impedance of a freshly-printed structure therefore transitions from a largely capacitive reactance on printing to a predominantly resistive response as the paste cures.

\section{Experimental}

Three carbon pastes were investigated in this research; the commercial paste ED4000 from Electrapolymer (Paste E), and two pastes from Gwent Electronic Materials (GEM 1 and GEM 2). Both $A C$ impedance and DC resistance measurements were performed on the test samples immediately after the conductive paste was printed onto pre-deposited electrodes. The samples were then placed into an oven to cure at $95^{\circ} \mathrm{C}$ for 40 minutes whilst the impedance and resistance were continually logged.

The uncertainty of measurement of the three pastes is based on five prints of Paste E, GEM 1, and GEM 2. The average and standard deviation were calculated from the AC measurements at time 0 . The impedance and phase were determined using 5 test frequencies at decade interval ranging from $100 \mathrm{~Hz}$ to $1 \mathrm{MHz}$.

To investigate the effect of temperature and particle loading, commercially available ED4000 paste was used. Five printed samples were cured at each of temperatures $55^{\circ} \mathrm{C}, 85^{\circ} \mathrm{C}, 95^{\circ} \mathrm{C}$ and 105 ${ }^{\circ} \mathrm{C}$. To investigate the effect of particle loading, ED4000, was mixed by weight with butyrolactone sourced from sigma Aldrich. Butyrolactone was the chemical advised by the paste manufacturer to be used in diluting the product when the product was in storage for some time. A Sartorius model AZ313 balance was used to weigh the samples. The particle loading of the unmixed paste was $60 \%$. Butyrolactone was added to decrease the particle loading to $48 \%, 52 \%$ and $56 \%$. Scanning Electron Microscope (SEM) images were taken using Camscan MX2500.

The following sections detail the pre-deposited electrodes, the printing of the test structures, the test jig to hold the test structures, and the electrical equipment set-up.

\section{Pre-deposited Electrodes}

Since probing directly on top wet paste was unreliable, electrodes were first deposited onto the PET substrate. The pre-deposited electrodes connect the test pins to the wet test structure shown in Figure 1. This prevents a direct contact of test pins to the sample that will cause physical defects and possibly erroneous measurement. The pre-deposited electrode was ED3000 from Electrapolymer, a silver filled paste. Figure 1 depicts the silver paste electrode design with $5 \mathrm{~mm}$ diameter probe pads locations with labels that correspond to the AC impedance analyser and DC resistance meter terminals. The test electrode design also includes eight $2 \mathrm{~mm}$ fiducial patterns that are used to align the structure screen design to the electrodes. 
Figure 1 The pre-deposited silver electrodes design and location of electrical probes
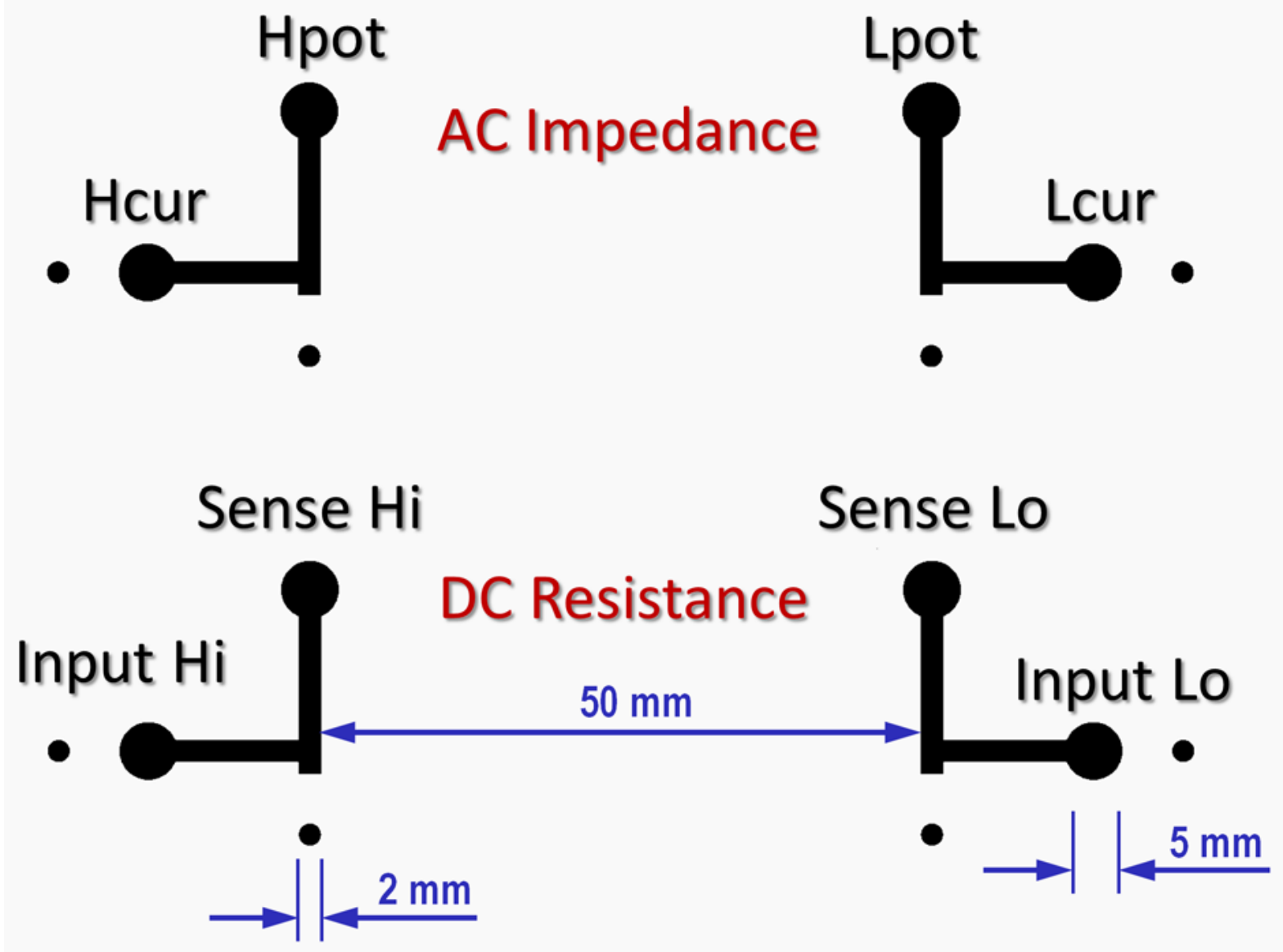

\section{Printed Test Structure}

The printing of the test structures, shown in Figure 3 began with the alignment of a test structure screen on top of the pre-deposited electrodes. The two sets of test structures in parallel were then printed simultaneously onto the $120 \mu \mathrm{m} \pm 10 \mu \mathrm{m}$ thick PET substrates. The dimensions of the test structure are $2 \mathrm{~mm}$ in width and $66 \mathrm{~mm}$ in length as depicted in Figure 2. The rectangular test structure overlaps the electrodes by $8 \mathrm{~mm}$ to provide a good electrical and mechanical contact between the electrodes and the device under test (DUT). The separation between the sensing electrodes was 50 $\mathrm{mm}$. 
Figure 2 The test structure screen design with fiducial patterns

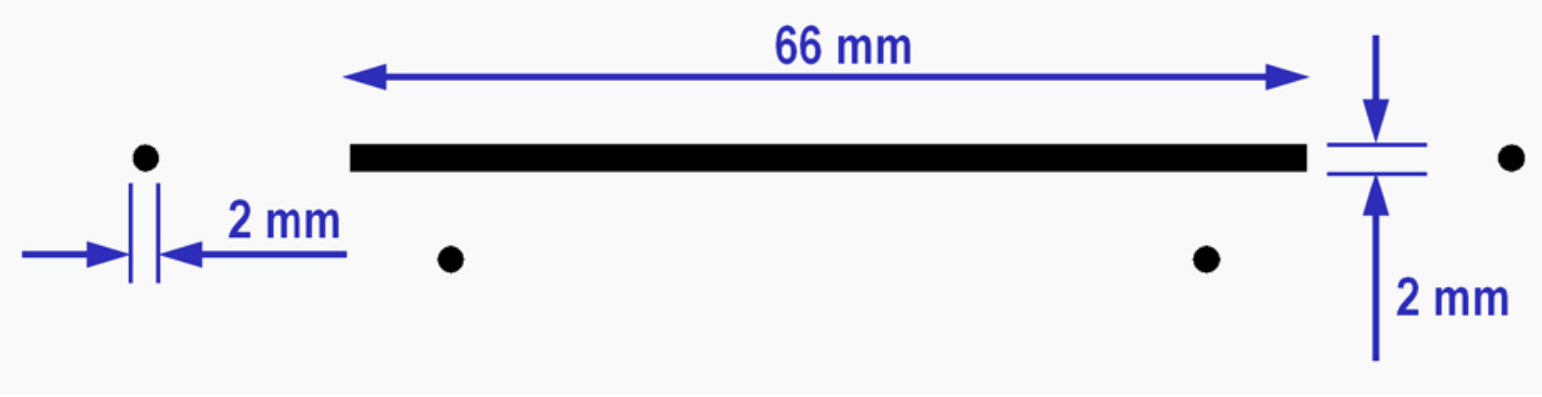

Three carbon filled pastes were used; Paste E, GEM 1 and GEM 2. Five prints of each paste were done to provide some statistical data and understanding into the repeatability of the measurement. Bode plots were used to interpret the result of the curing. All pastes were cured in a convection oven at $95^{\circ} \mathrm{C}$ for 40 minutes.

A screen was manufactured by $\mathrm{MCl}$ Precisions Itd. The polyester screen was 6 inch wide, 8 inch long, using a $27 / 140$ mesh, $45^{\circ}$ angle mesh orientation and $18 \mu \mathrm{m}$ emulsion thickness. A rubber squeegee was used to manually transfer the paste to the substrate. The samples were placed in the test interface and set to cure in the convection oven.

\section{Test Jig}

Measurement of printed electronics at elevated temperature was made possible using a test interface. The test interface shown in Figure 3 was built to provide electrical connection between the sample and the test equipment. The test interface is made out of two $4 \mathrm{~mm}$ thick Tufnol sheets. The top plate holds the spring loaded pins that maintain electrical contact between test equipment and the test structure. The bottom plate contains the DUT. Fasteners at each corner keep both plates together and maintain the test pin to DUT pad connections. 
Figure 3 Photo of the test interface with device under test

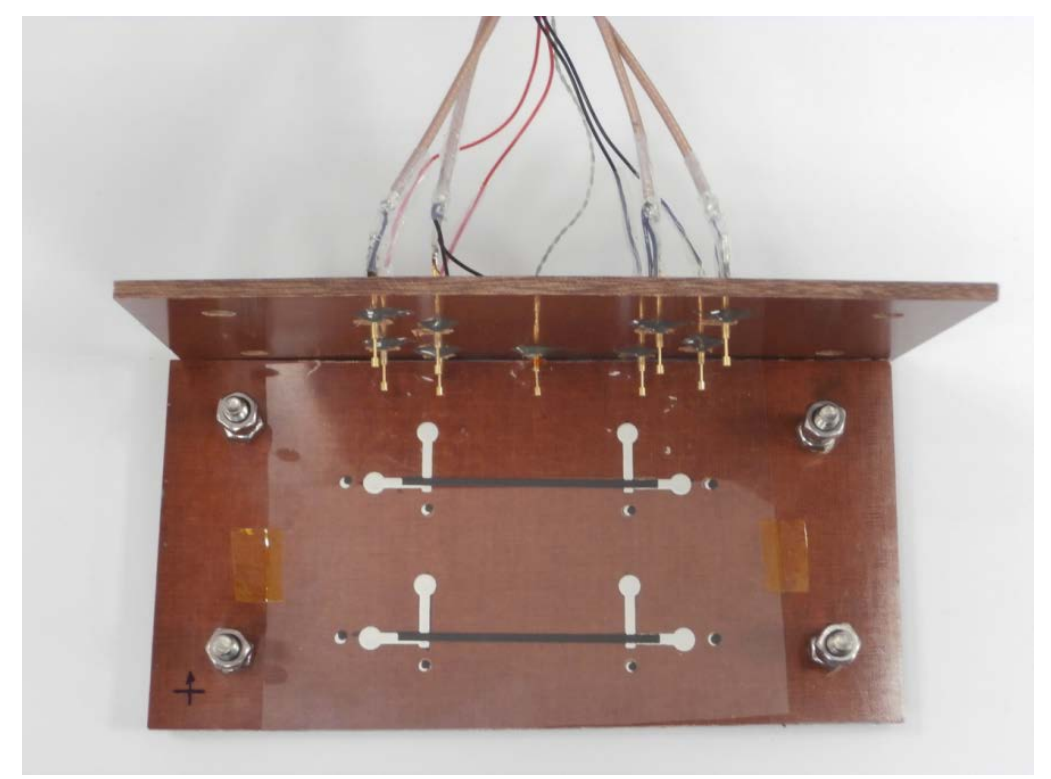

\section{Electrical Measurements}

The measurement setup shown in Figure 4 provides the continuous measurement of AC Impedance, DC resistance and temperature of the DUT during cure. Impedance measurement was performed using an Agilent 4294A impedance analyser, which was set to sweep the frequency from $100 \mathrm{~Hz}$ to $1 \mathrm{MHz}$. Each sweep took $6.5 \pm 0.5$ seconds.

The DC resistance was measured using a Keithley 2010 multimeter which has an upper range of $100 \mathrm{M} \Omega$. A LabVIEW program was written to control the convection oven, impedance analyser and multimeter. Four-probed measurement was used on both AC impedance and DC resistance measurements to eliminate the effect of probe lead resistance. The temperature was measured by a K-type thermocouple placed on the substrate $1 \mathrm{~cm}$ from the structure under test. A National Instruments (NI) PCl-6251 data acquisition card to convert analogue signal to digital signal was installed in the computer. The NI BNC-2010 temperature interface was used to connect the thermocouple to the data acquisition card. Immediately after printing the test structure was placed in the jig, fastened, and electrical monitoring initiated before being placed into a Memmert UFP400 convection oven to cure the samples at $55^{\circ} \mathrm{C}, 85^{\circ} \mathrm{C}, 95^{\circ} \mathrm{C}$ and $105^{\circ} \mathrm{C}$ for 40 minutes. 
Figure 4 Block diagram of the test setup for electrical measurement

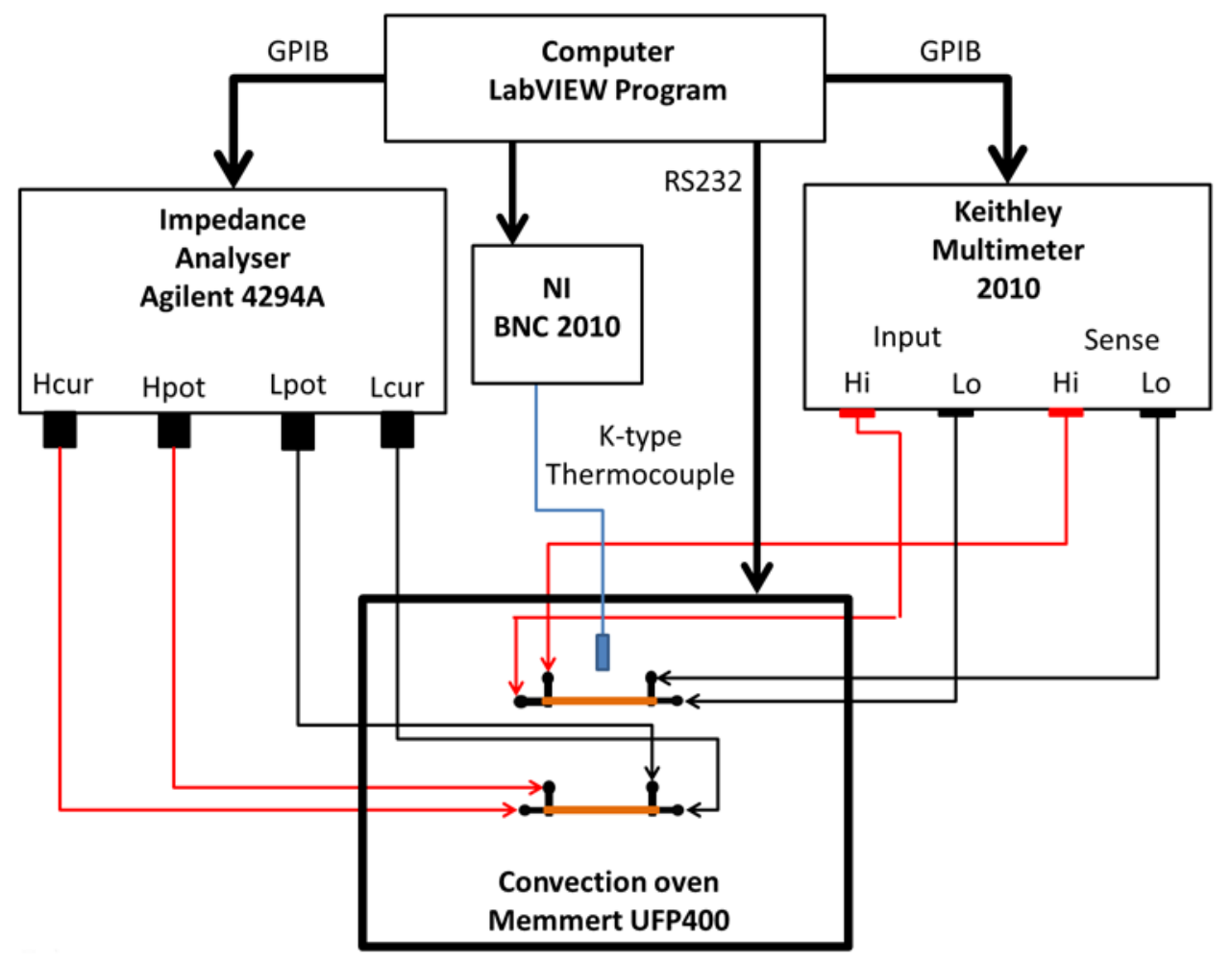

\section{Results and Discussion}

Five repeats of three carbon film pastes were carried out with continuous monitoring of their $A C$ impedance and DC resistance during curing at $95{ }^{\circ} \mathrm{C}$ for 40 minutes. Figure 5 depicts the $\mathrm{AC}$ impedance and DC resistance measurement during the cure of the Paste $\mathrm{E}$ printed structure. 
Figure 5 The $A C$ impedance and $D C$ resistance measurement during cure at $95^{\circ} \mathrm{C}$ for Paste $\mathrm{E}$

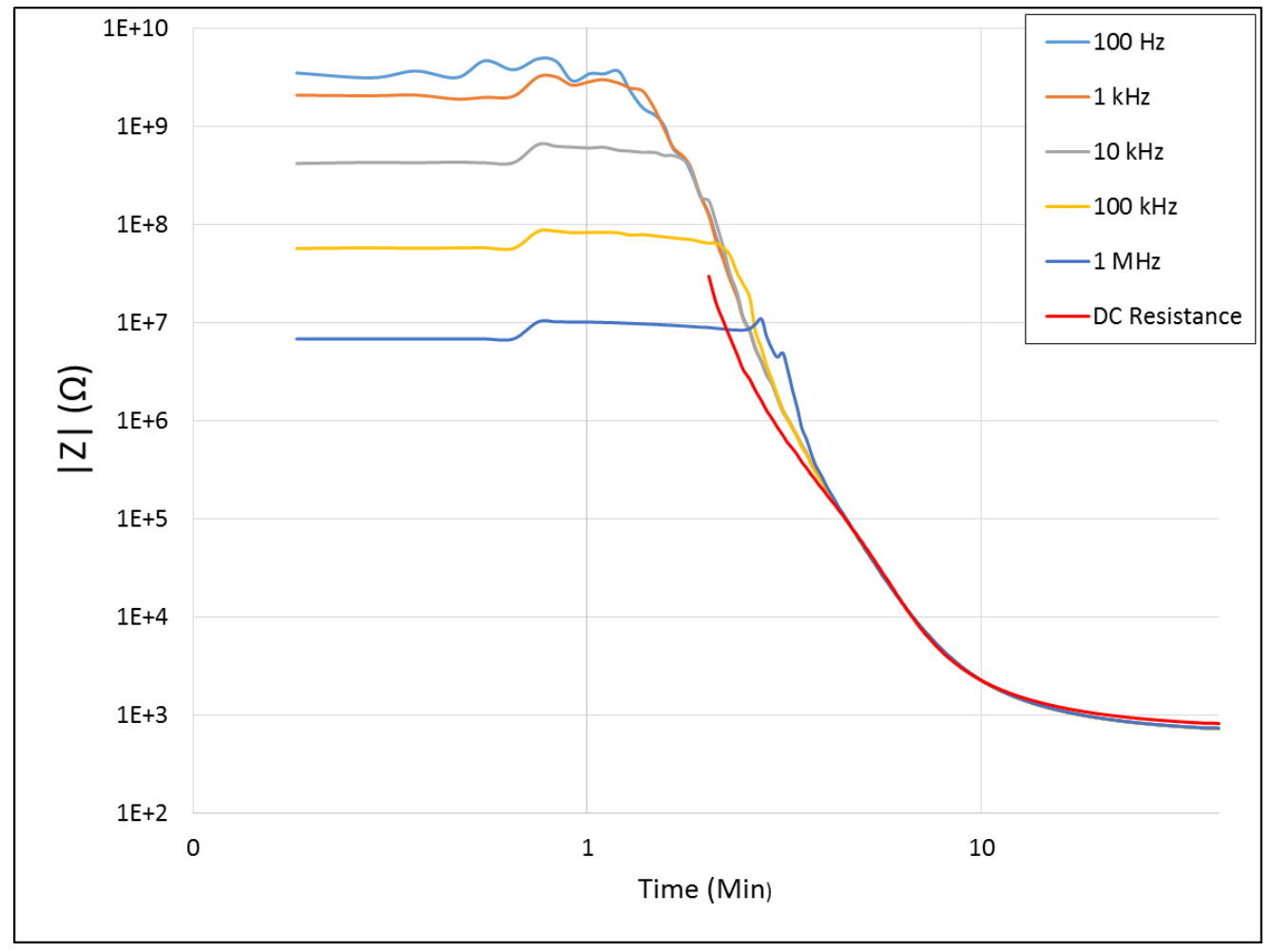

Figure 6 The $A C$ impedance and DC resistance measurement during cure at $95^{\circ} \mathrm{C}$ for GEM 1

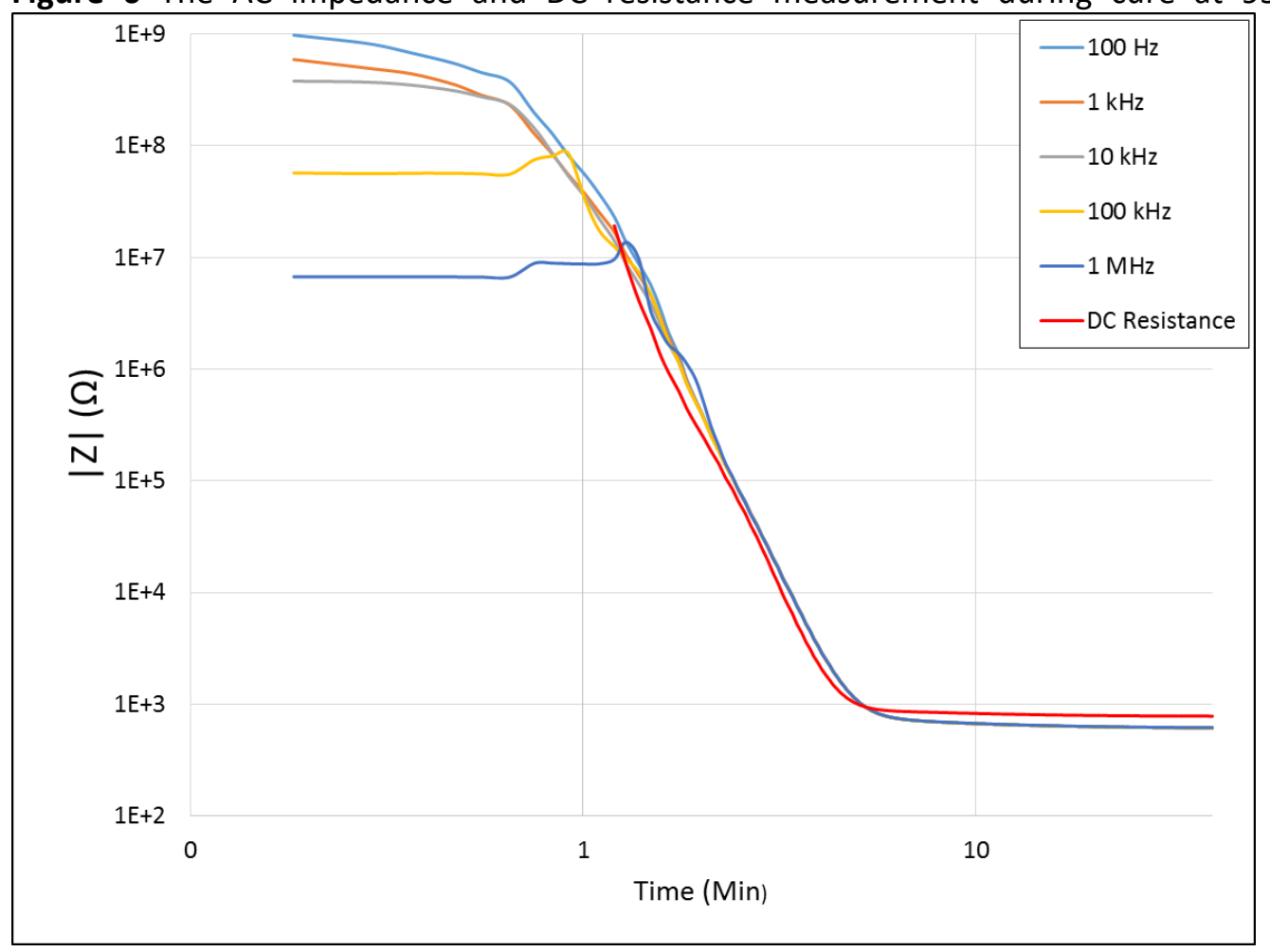


Figure 7 The $A C$ impedance and $D C$ resistance measurement during cure at $95^{\circ} \mathrm{C}$ for GEM 2

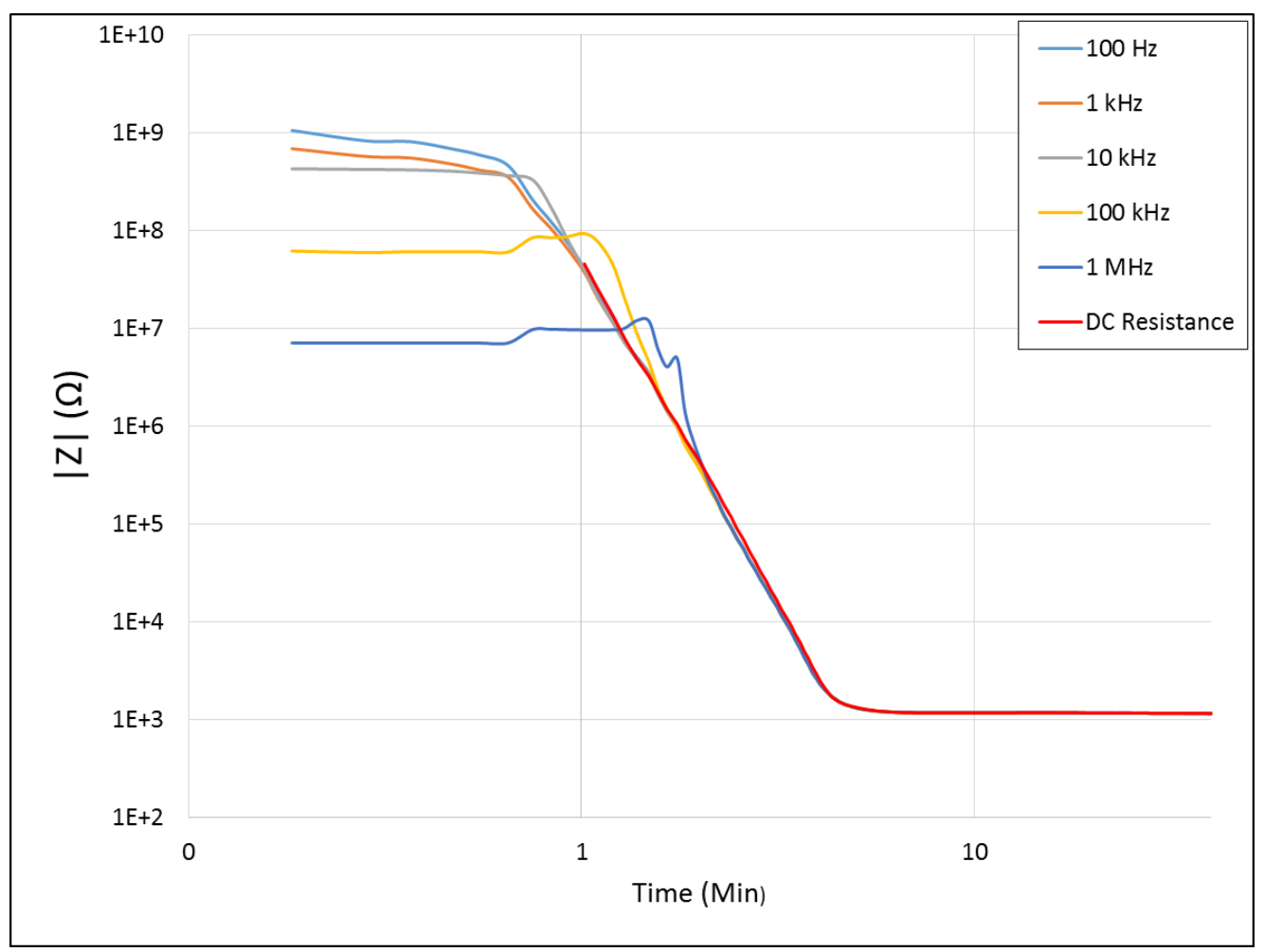

The initial measurements of the parallel test structures have produced test results for $A C$ impedance as shown in Figure 5, Figure 6 and Figure 7 or Paste E, GEM 1 and GEM 2 respectively. This is because the AC impedance analyser can measure higher impedance range than the DC resistance meter which was limited to $100 \mathrm{M} \Omega$. Interestingly the change in AC Impedance test frequency affects the impedance of the test structure. This is better understood by considering the relationship between impedance, reactance and resistance:

$$
Z=\sqrt[2]{R^{2}+X_{C}^{2}}
$$

Where $Z$ is impedance expressed in $\Omega, R$ is the Resistance in $\Omega$ and $X_{c}$ is the capacitive reactance expressed in $\Omega$. The formula for reactance is:

$$
X_{c}=\frac{1}{2 \pi f C}
$$

Where $X_{c}$ is capacitive reactance expressed in $\Omega, f$ is the test frequency in $\mathrm{Hz}$ and $C$ is the capacitance of the printed structure. The initial $A C$ impedance test frequency has an inversely proportional relationship to printed structure impedance magnitude since the impedance is dominated by the reactance. This is what we observe for the initial impedance measurements, with the impedance magnitude decreasing as measurement frequency is increased.

After sample curing had commenced, the DC resistance started to decrease in value as vehicle curing caused particle to particle contact. As the DC resistance of the test structures decreased, the $A C$ impedance measurements converged with the DC resistance measurements. This is because the paste vehicle that hinders the electric current from passing through the test structure has cured, bringing the conductive particulate into close contact and decreasing the resistive component of the 
impedance. The last frequency to converge was $1 \mathrm{MHz}$ since the reactance component at this frequency was lower (Equation 2).

Further curing of the test sample will cause a decreasing level of change in the DC resistance and AC impedance measurements. At the end of the 40 minutes cure, a low resistance structure is achieved, although its resistance, as is typical with printed pastes, will continue to decrease a little further for a few days at room temperature (Inoue, Suganuma 2006, Perelaer, De Laat et al. 2008). Whilst curing at high temperature for longer would decrease the resistivity further and faster, it will have a negative impact on the structural properties of the substrate.

Figure 8 SEM image of Paste $E$

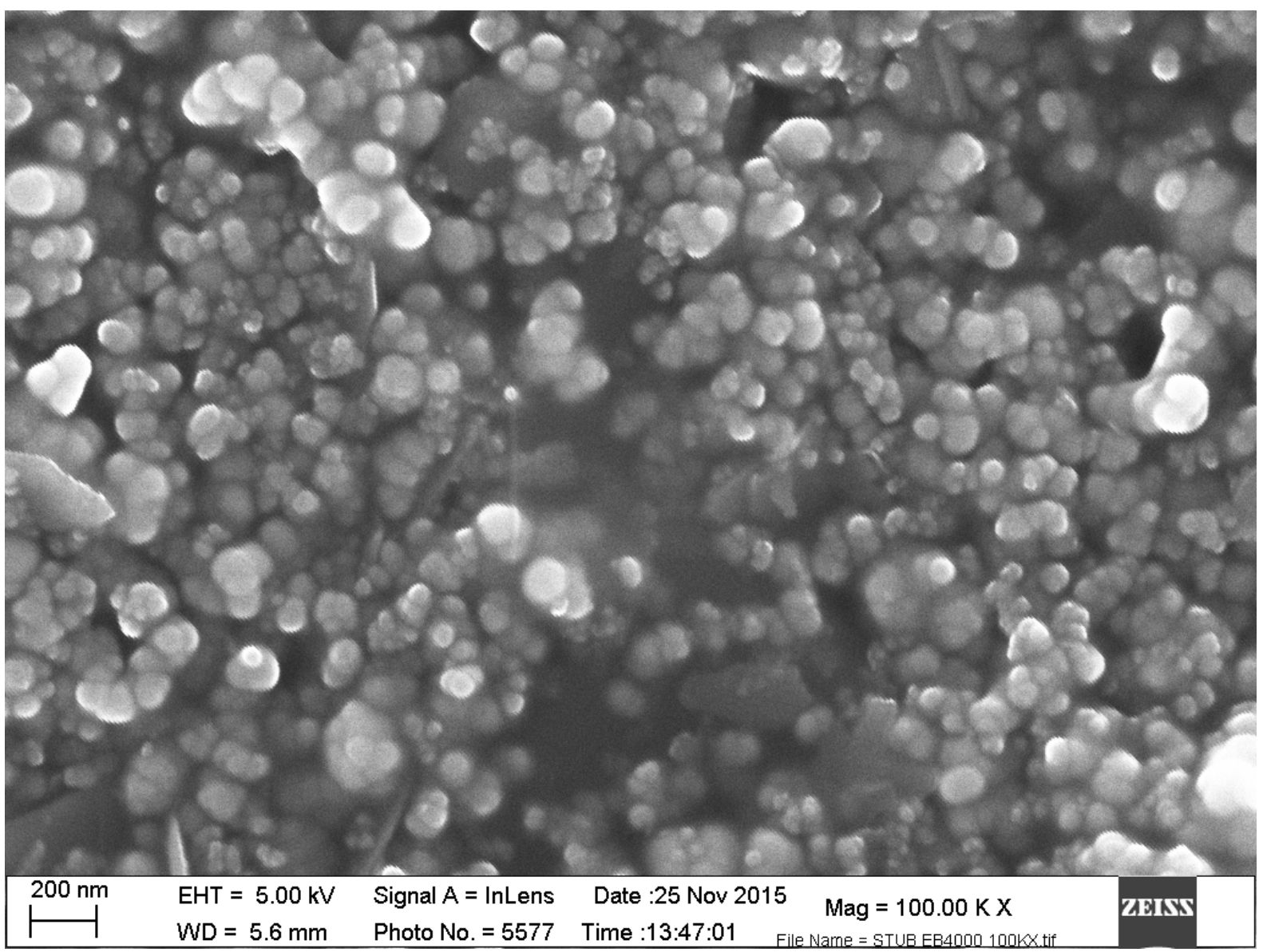


Figure 9 SEM image of GEM 1

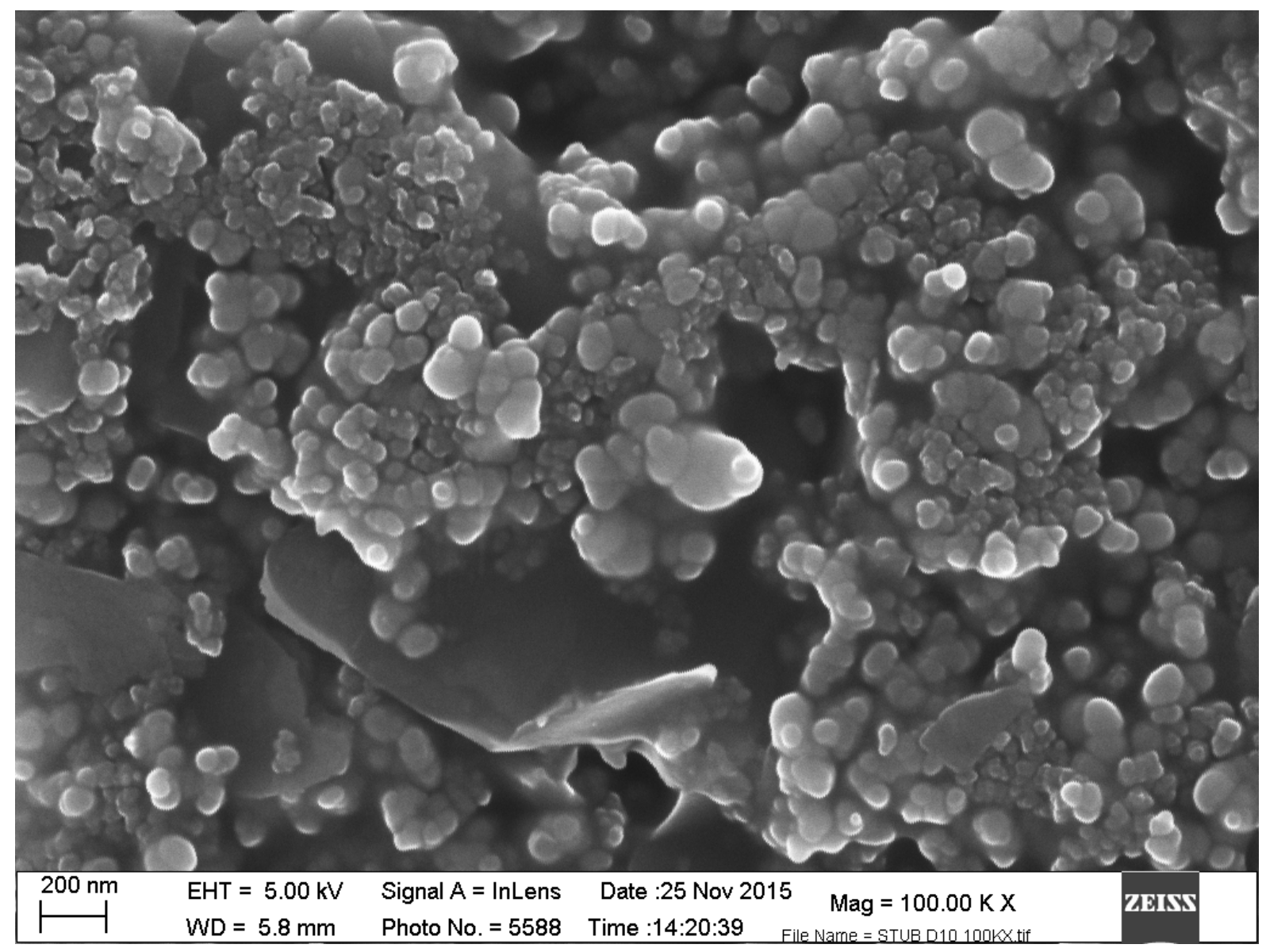




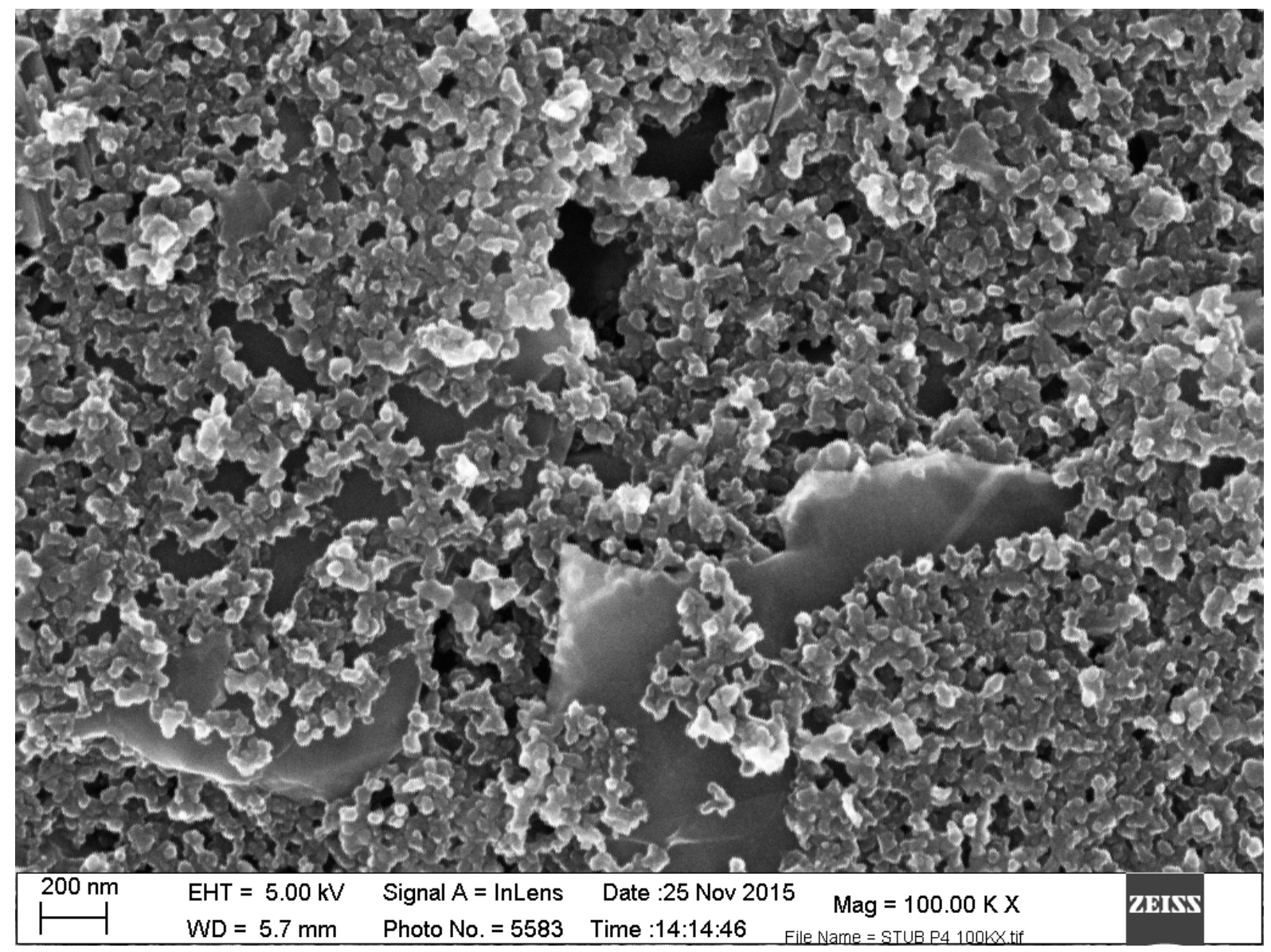

The SEM images taken from Paste E, GEM 1 and GEM 2 pastes indicate that the particles in the GEM 2 paste are finer and the overall structure is more dense than in Paste E and GEM 1. This could be a reason why the $A C$ and DC Resistance after curing are the same for the GEM 2 sample, whereas for both the Paste E and GEM 1 samples the DC resistance value is higher than that of the AC impedance after 40 minutes of curing at $95^{\circ} \mathrm{C}$. At this stage of cure there are two main components that are left in the printed structure. First is the electrical component in the form of conductive particles and second, the mechanical component which is the adhesive to hold the particles together, and bind the structure to the substrate. The reason why the DC resistance is higher than the AC impedance for Paste E and GEM 1 is that Paste E and GEM 1 have more voids and spaces created between the large particles. The residual adhesive does not necessarily fill in between each of the large particles. The larger voids cause the DC resistance to increase.

Impedance measurement shows the indirect rate of solvent loss of the pastes and it differs from paste to paste. Within 10 minutes of placing GEM paste test prints into the oven, measurement shows an impedance value that is near to 40 minutes cured resistance value. On the other hand, the Electrapolymer paste requires more than 10 minutes to reach the cured resistance value. The final resistance value of Paste $E$ and GEM 1 pastes after 40 minutes of curing was below $1 \mathrm{k} \Omega$, while GEM 2 paste is higher than these two pastes and above $1 \mathrm{k} \Omega$. 
Figure 11 The phase measurement during cure at $95^{\circ} \mathrm{C}$ for Paste $\mathrm{E}$

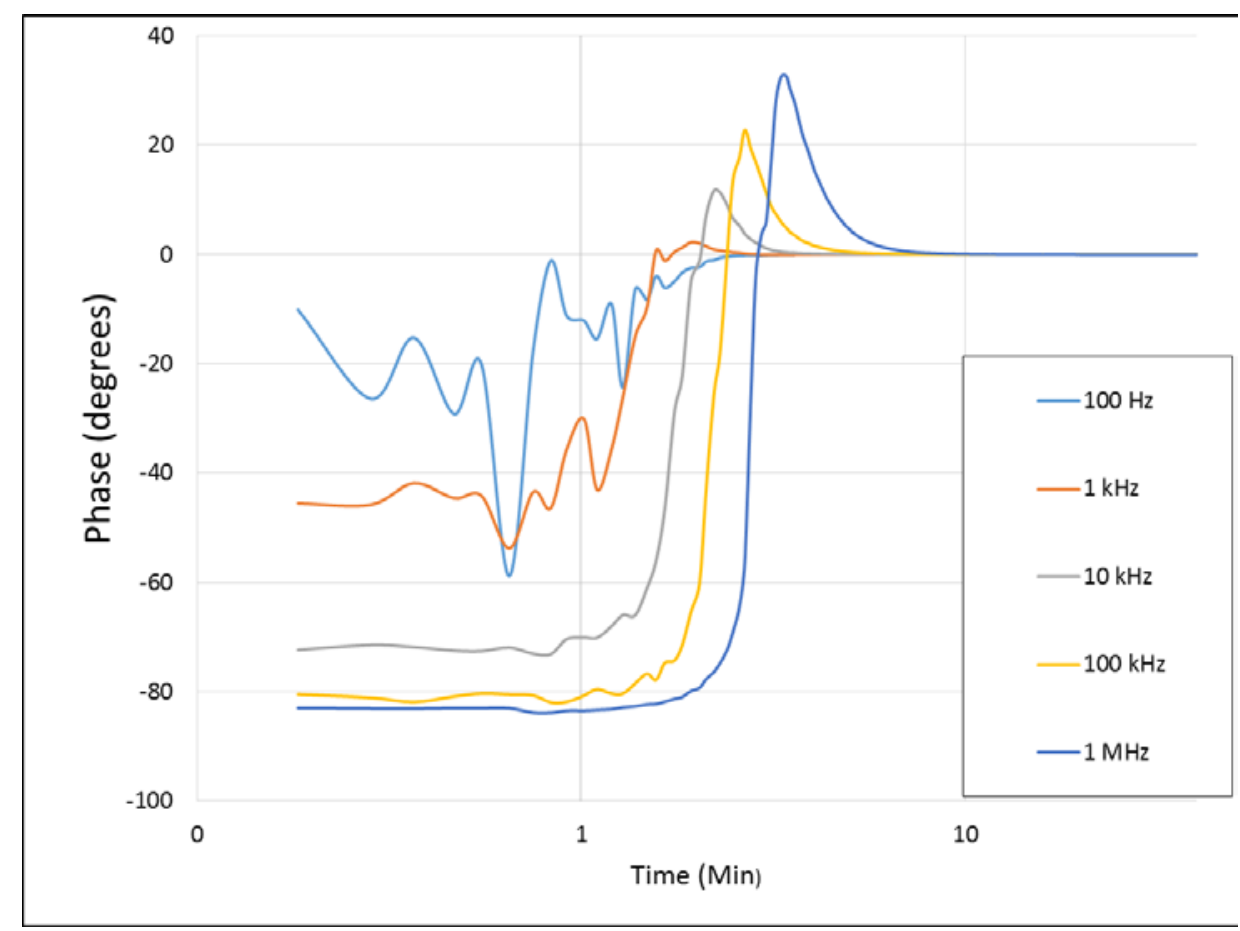

Figure 12 The phase measurement during cure at $95^{\circ} \mathrm{C}$ for GEM 1

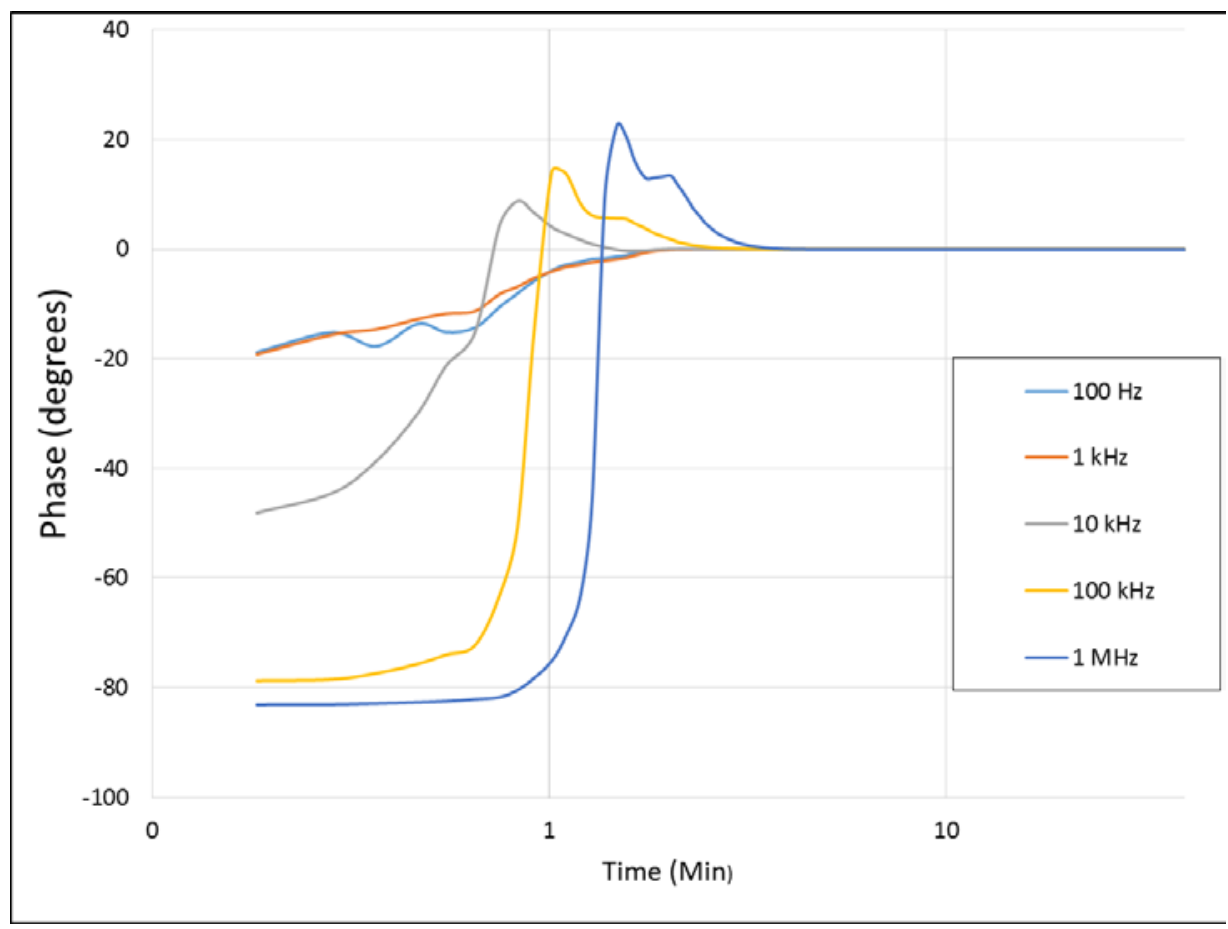


Figure 13 The phase measurement during cure at $95^{\circ} \mathrm{C}$ for GEM 2

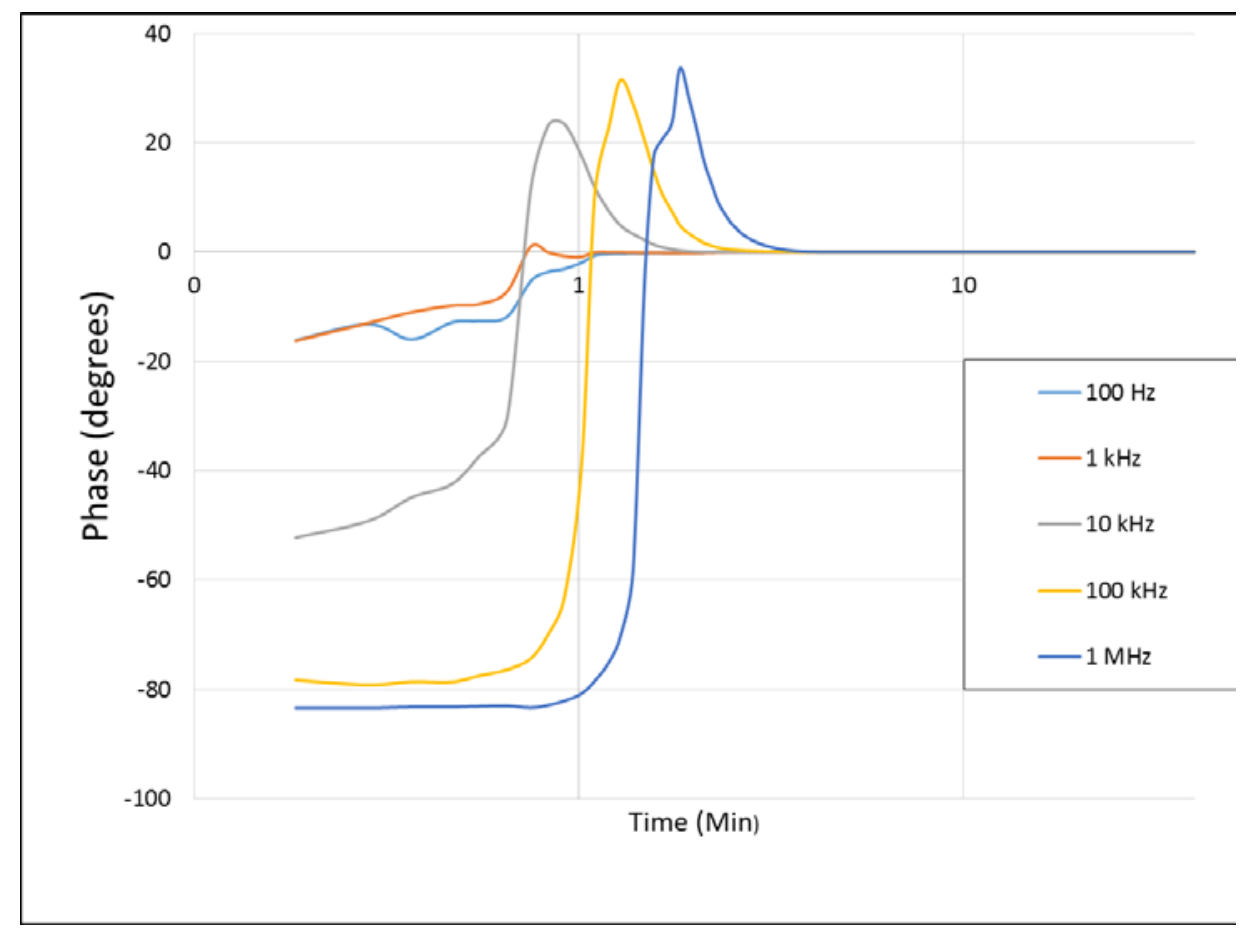

The initial measurements are taken when the pastes are still at liquid state. The phase measurement as shown in Figure 11 at this stage is between $-10^{\circ}$ to $-90^{\circ}$ to suggest that the device under test exhibits a purely capacitive component. The manufacturer datasheet for Paste $\mathrm{E}$ states that it contains $40 \%$, solvent and remainder is a combination of adhesive and conductive particle. The relationship between phase measurement and test frequency based on Equation 4 is more prominent at higher test frequency.

The relationship between frequency and phase is given by the Equation 4 .

$$
\theta=\tan ^{-1}\left(\frac{-X c}{R}\right)
$$

Where theta is the phase in degrees, and R is the resistance in ohms $(\Omega)$. Substituting the formula of $X c$ gives:

$$
\theta=\tan ^{-1}\left(-\frac{1}{2 \pi f C R}\right)
$$

Where $\theta$ is the phase in degree $\left({ }^{\circ}\right), f$ is the test frequency in hertz $(\mathrm{Hz})$, and $\mathrm{C}$ is the capacitance in farad. Based on the Equation 4, the effect of increasing the test frequency is a decrease in phase.

The sample was then placed into oven for further measurement. Using a high test frequency, $1 \mathrm{MHz}$, is better because it can detect residual solvent in printed electronics. As the paste cures, the phase moves from $-90^{\circ}$ towards $0^{\circ}$ suggesting that the initial capacitive structure is turning into a 
resistive structure. The phase measurement of $0^{\circ}$ at $1 \mathrm{MHz}$ test frequency means that fully cured printed electronics has been achieved, and that the test structure is a purely resistive device.

Table 1 Initial impedance and standard deviations values for Paste E, GEM 1 and GEM 2 structures between $100 \mathrm{~Hz}$ and $1 \mathrm{MHz}$

\begin{tabular}{|c|c|c|c|c|c|c|}
\hline Frequency & $\begin{array}{l}\text { Impedance } \\
(\Omega) \text { Paste } E\end{array}$ & $\begin{array}{c}\text { Impedance } \\
(\Omega) \text { GEM } 1\end{array}$ & $\begin{array}{l}\text { Impedance } \\
(\Omega) \text { GEM } 2\end{array}$ & $\begin{array}{l}\text { Standard } \\
\text { Deviation } \\
\text { (\%)Paste E }\end{array}$ & $\begin{array}{l}\text { Standard } \\
\text { Deviation } \\
\text { (\%)GEM } 1\end{array}$ & $\begin{array}{l}\text { Standard } \\
\text { Deviation } \\
\text { (\%)GEM } 2\end{array}$ \\
\hline $100 \mathrm{~Hz}$ & $3.52 \mathrm{E}+10^{9}$ & $9.76 \mathrm{E}+10^{8}$ & $1.06 \times 10^{9}$ & 22.91 & 20.35 & 22.49 \\
\hline $1 \mathrm{kHz}$ & $2.08 \mathrm{E}+10^{9}$ & $5.92 \mathrm{E}+10^{8}$ & $6.88 \mathrm{E}+10^{8}$ & 40.53 & 19.75 & 15.63 \\
\hline $10 \mathrm{kHz}$ & $4.20 \mathrm{E}+10^{8}$ & $3.79 \mathrm{E}+10^{8}$ & $4.28 \mathrm{E}+10^{8}$ & 24.22 & 9.30 & 2.85 \\
\hline $100 \mathrm{kHz}$ & $5.72 \mathrm{E}+10^{7}$ & $5.70 \mathrm{E}+10^{7}$ & $6.19 \mathrm{E}+10^{7}$ & 16.83 & 2.36 & 4.06 \\
\hline $1 \mathrm{MHz}$ & $6.85 \mathrm{E}+10^{6}$ & $6.70 \mathrm{E}+10^{6}$ & $7.12 \mathrm{E}+10^{6}$ & 11.51 & 3.69 & 4.88 \\
\hline
\end{tabular}

The impedance repeatability of the printing process on the uncured Paste E, GEM 1 and GEM 2 paste is shown in Table 1 for the range of frequencies investigated. The impedance measurement of the printed structure during its liquid phase produced a large variation at low test frequency, whilst frequencies in excess of $10 \mathrm{kHz}$ permitted stable measurements. Based on $1 \mathrm{MHz} \mathrm{AC}$ Impedance measurement, it produces the lowest impedance measurement that is near to the cured DC resistance values and lowest standard deviation. The DC resistance measurement represents the electrical characteristic of a fully cured printed electronic structure.

Table 2 Initial phase and standard deviations values for Paste E, GEM 1 and GEM 2 structures between $100 \mathrm{~Hz}$ and $1 \mathrm{MHz}$

\begin{tabular}{|c|c|c|c|c|c|c|}
\hline $\begin{array}{c}\text { Frequency } \\
(\mathrm{Hz})\end{array}$ & $\begin{array}{c}\text { Paste } \\
\mathrm{E} \\
\text { Phase } \\
\left({ }^{\circ}\right)\end{array}$ & $\begin{array}{c}\text { GEM 1 } \\
\text { Phase } \\
\left({ }^{\circ}\right)\end{array}$ & $\begin{array}{c}\text { GEM 2 } \\
\text { Phase } \\
\left({ }^{\circ}\right)\end{array}$ & $\begin{array}{c}\text { Paste E } \\
\text { Standard } \\
\text { Deviation } \\
(\%)\end{array}$ & $\begin{array}{c}\text { GEM 1 } \\
\text { Standard } \\
\text { Deviation } \\
(\%)\end{array}$ & $\begin{array}{c}\text { GEM 2 } \\
\text { Standard } \\
\text { Deviation } \\
(\%)\end{array}$ \\
\hline $100 \mathrm{~Hz}$ & -48 & -19 & -16 & 28.4 & 10 & 20 \\
\hline $1 \mathrm{kHz}$ & -68 & -19 & -16 & 0.9 & 10 & 15 \\
\hline $10 \mathrm{kHz}$ & -81 & -48 & -52 & 0.44 & 14 & 8 \\
\hline $100 \mathrm{kHz}$ & -86 & -79 & -78 & 0.37 & 2.3 & 1.5 \\
\hline $1 \mathrm{MHz}$ & -86 & -83 & -83 & 0.02 & 0.33 & 0.38 \\
\hline
\end{tabular}

The phase measurements of wet conductive test structure at (TO) together with noise information over the range of frequency are shown in Table 2. The phase measurement, similar to that of impedance measurement, of wet conductive paste produces large variation at low frequency, and less measurement variation at $1 \mathrm{MHz}$ test frequency. In addition, measurement at $1 \mathrm{MHz}$ produces a result that is near to $-90^{\circ}$ phase which is the exact representation of a purely capacitive element. This clearly defines that the test structure is wet and in liquid phase. 
Figure 14 The $\mathrm{AC}$ Impedance measurement at $1 \mathrm{MHz}$ for Paste $\mathrm{E}$ structures cured at different temperature for 40 minutes

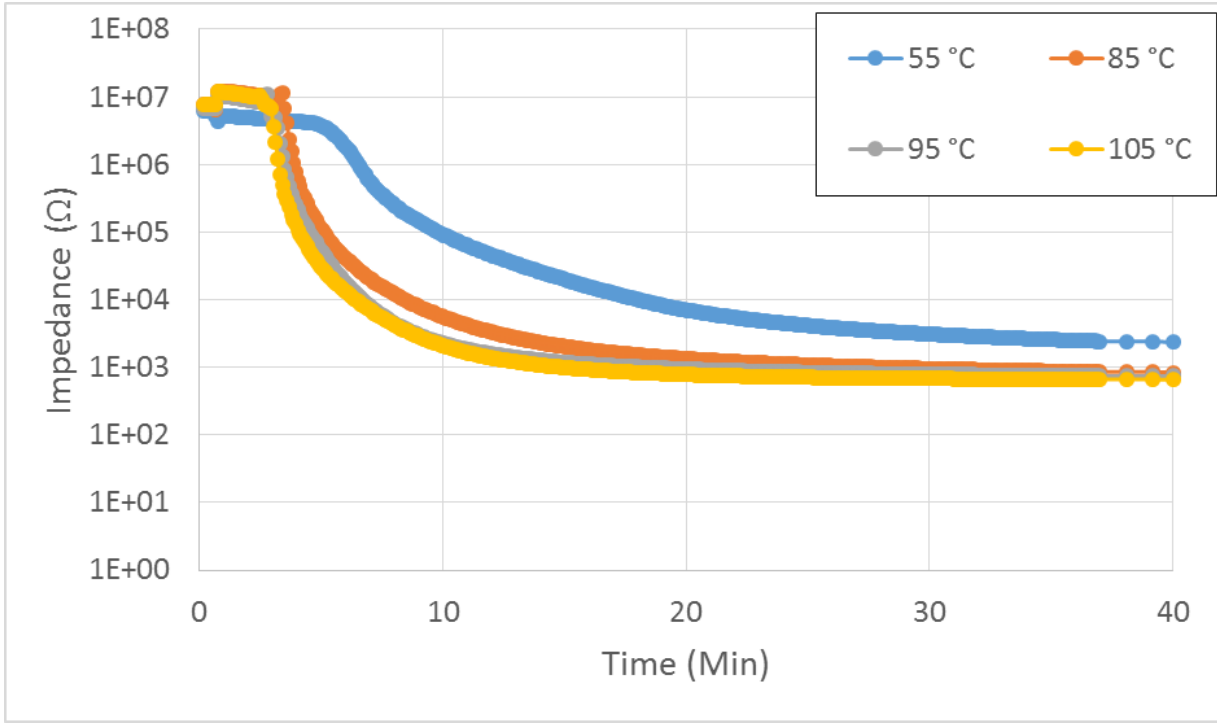

The initial impedance measurements at $1 \mathrm{MHz}$ of Paste E samples that are intended to be cured at different temperatures are the same, regardless of their curing temperature. The initial impedance measurement of the sample cured at $55^{\circ} \mathrm{C}$ was left unchanged even after placing it into the oven. In comparison the samples placed into the oven at $85{ }^{\circ} \mathrm{C}, 95{ }^{\circ} \mathrm{C}$ and $105{ }^{\circ} \mathrm{C}$ temperatures the sudden increase in impedance could be due to the expansion of the solvent or the polymer binder that is present in the paste.

Increasing the curing temperature will make the conductive paste cure faster because it causes the solvent evaporation rate to increase. Subsequently this causes the rate of particle to particle contact to increase and the impedance measurement to decrease. In addition to the removal of solvent from the test structure, the higher temperature will cause further polymerisation of adhesive causing it to shrink and pull the conductive particles closer to each other (Pefferkorn 2012, Schneider, Cavalcante et al. 2010, Pires-de-Souza, Drubi Filho et al. 2009, Greer, Street 2007). The shrinking of polymer depends on the glass transition temperature of the polymer. The curing temperature must pass this temperature to be able to cause the polymer to shrink.

The effect of different curing temperature causes the delay of percolation threshold which causes the measured resistance to increase after 40 minutes of curing. The delay of the measured impedance to decrease is observed when $1 \mathrm{MHz}$ test frequency was used. Another change on the plot caused by temperature is changing the resistance of cured printed electronics. This will have an effect with the ratio between $\mathrm{T} 0$ and $\mathrm{T} 40$. 
Figure 15 Impedance measurement at $1 \mathrm{MHz}$ of Paste $\mathrm{E}$ at different particle loading

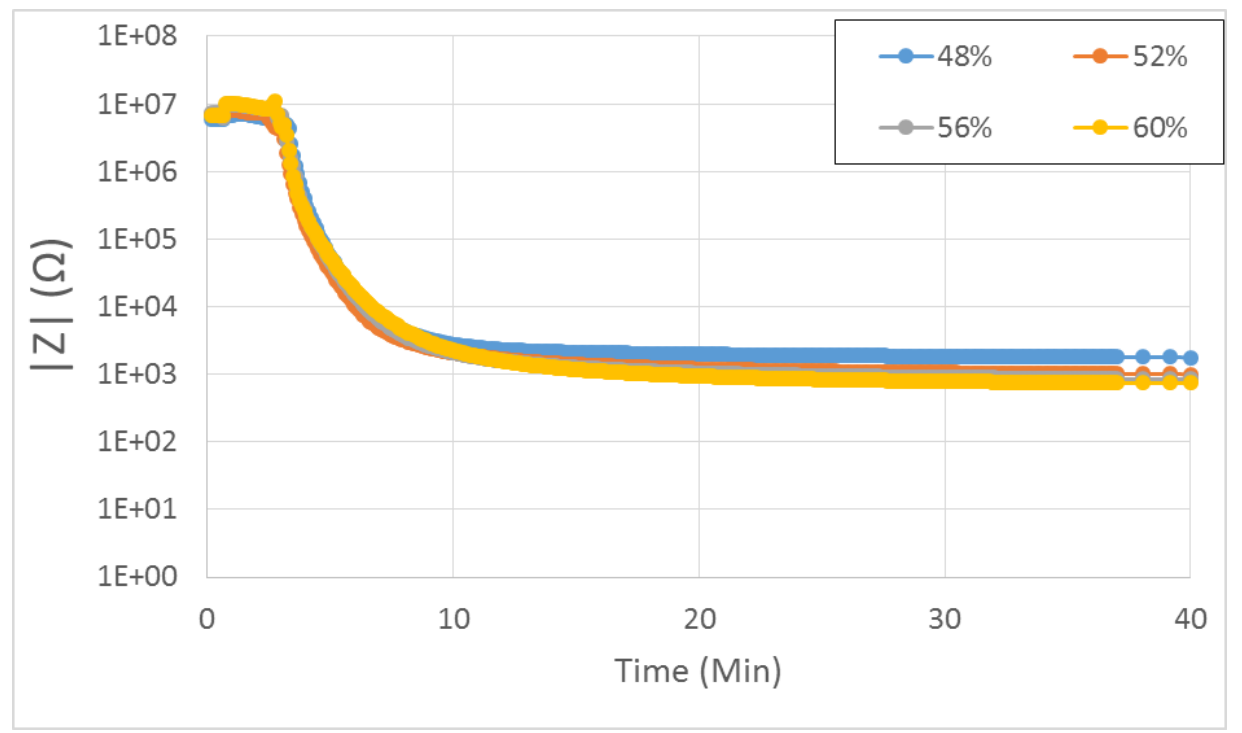

Particle loading was adjusted by adding solvent that the manufacturer advised use of to prevent the paste from drying. Decreasing the particle content of Paste $E$ has caused faster curing and a higher impedance value after 40 minutes of curing at $95^{\circ} \mathrm{C}$. In Figure 16 the pastes with less particle content, particularly the extreme case of $48 \%$ content, achieved their final impedance values faster than that of the $60 \%$ particle loaded paste. However, this does not mean that faster curing provides a lower final electrical impedance. The amount and intrinsic resistivity value of the conductive particles have dictated the final cured value of the printed electronics.

Table 3 shows the DC measurements performed on the three different cured print pastes. Average and standard deviation of the measurements were calculated.

Table 3 Final DC resistance for Paste E, GEM 1 and GEM 2 pastes

\begin{tabular}{|c|c|c|c|c|c|c|c|}
\hline $\begin{array}{c}\text { Paste } \\
\text { Name }\end{array}$ & $\begin{array}{c}\text { Sample 1 } \\
(\Omega)\end{array}$ & $\begin{array}{c}\text { Sample } \\
2(\Omega)\end{array}$ & $\begin{array}{c}\text { Sample } \\
3(\Omega)\end{array}$ & $\begin{array}{c}\text { Sample } \\
4(\Omega)\end{array}$ & $\begin{array}{c}\text { Sample 5 } \\
(\Omega)\end{array}$ & $\begin{array}{c}\text { Average } \\
(\Omega)\end{array}$ & $\begin{array}{c}\text { Standard } \\
\text { deviation } \\
(\%)\end{array}$ \\
\hline Paste E & 716 & 727 & 718 & 857 & 810 & 766 & 8 \\
\hline GEM 1 & 770 & 710 & 902 & 871 & 657 & 782 & 12 \\
\hline GEM 2 & 1133 & 1262 & 1159 & 1105 & 1166 & 1165 & 5 \\
\hline
\end{tabular}

The DC resistance measurement after 40 minutes (T40) at $95^{\circ} \mathrm{C}$ curing is shown in Table 3 . Considering all are carbon pastes, Paste E and GEM 1 values are close to each other while GEM 2 produces the highest resistance. The increase in resistance for GEM 2 test prints could be due to contamination or highly resistive material present in the test structure other than carbon particles. 
Figure 16 The $D C$ resistance measurements of Paste $E$ after 40 minutes at different curing temperature

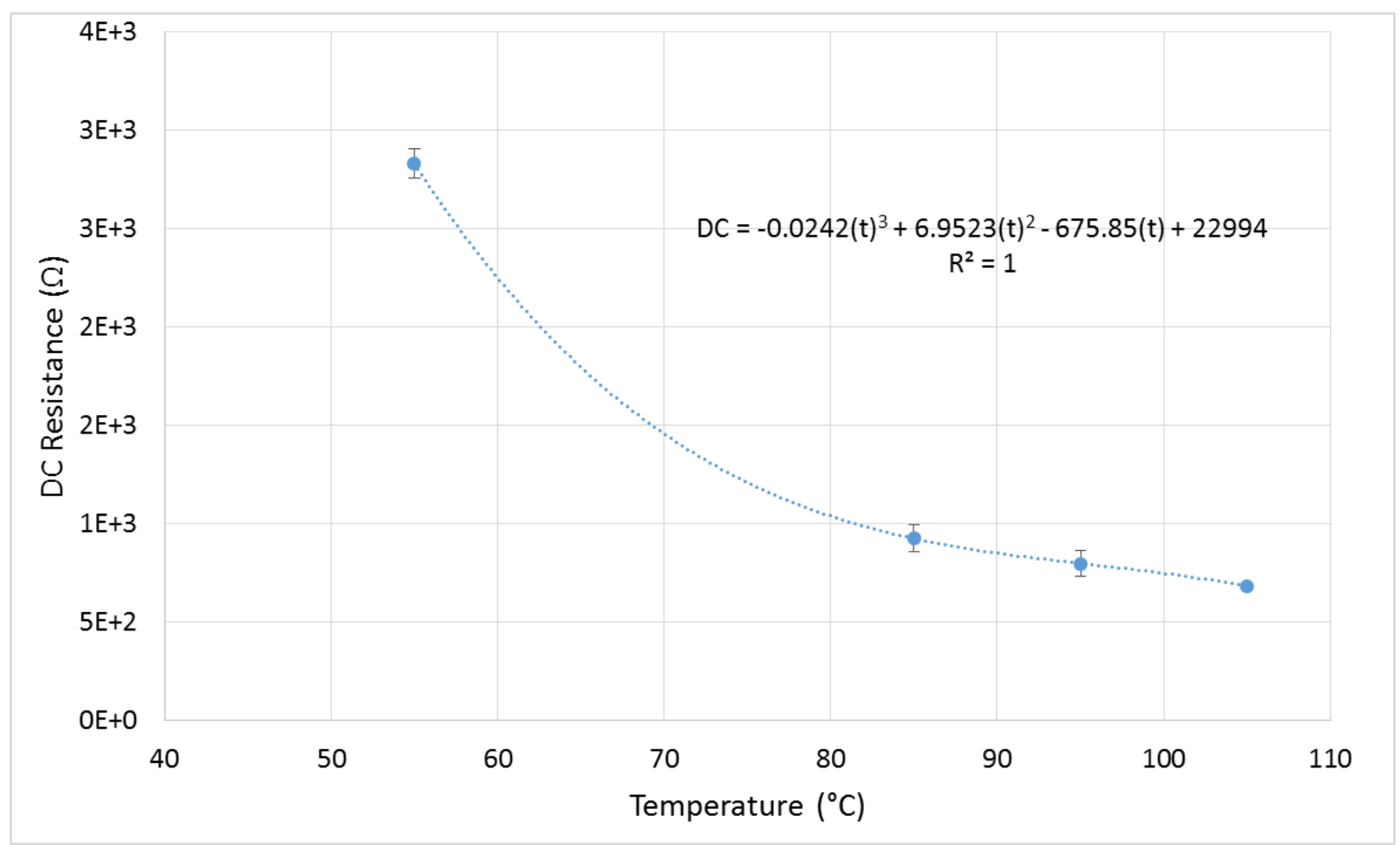

Increasing the curing temperature caused the DC resistance at (T40) to decrease as shown in Figure 16. The model for Paste $E$ at different level of curing is shown in the Figure 16, where $t$ is the curing temperature in Celsius. Curing the test structure at $105^{\circ} \mathrm{C}$ has produced a final DC resistance of 684 $\Omega$, whilst $2.8 \mathrm{k} \Omega$ was obtained at a cure temperature of $55^{\circ} \mathrm{C}$. The increase in temperature of cure has increased the rate of evaporation of solvent and thereby reduced the resistance measured after 40 minutes.

Figure 17 The DC resistance measurements after 40 minutes of Paste $E$ at different particle loading 


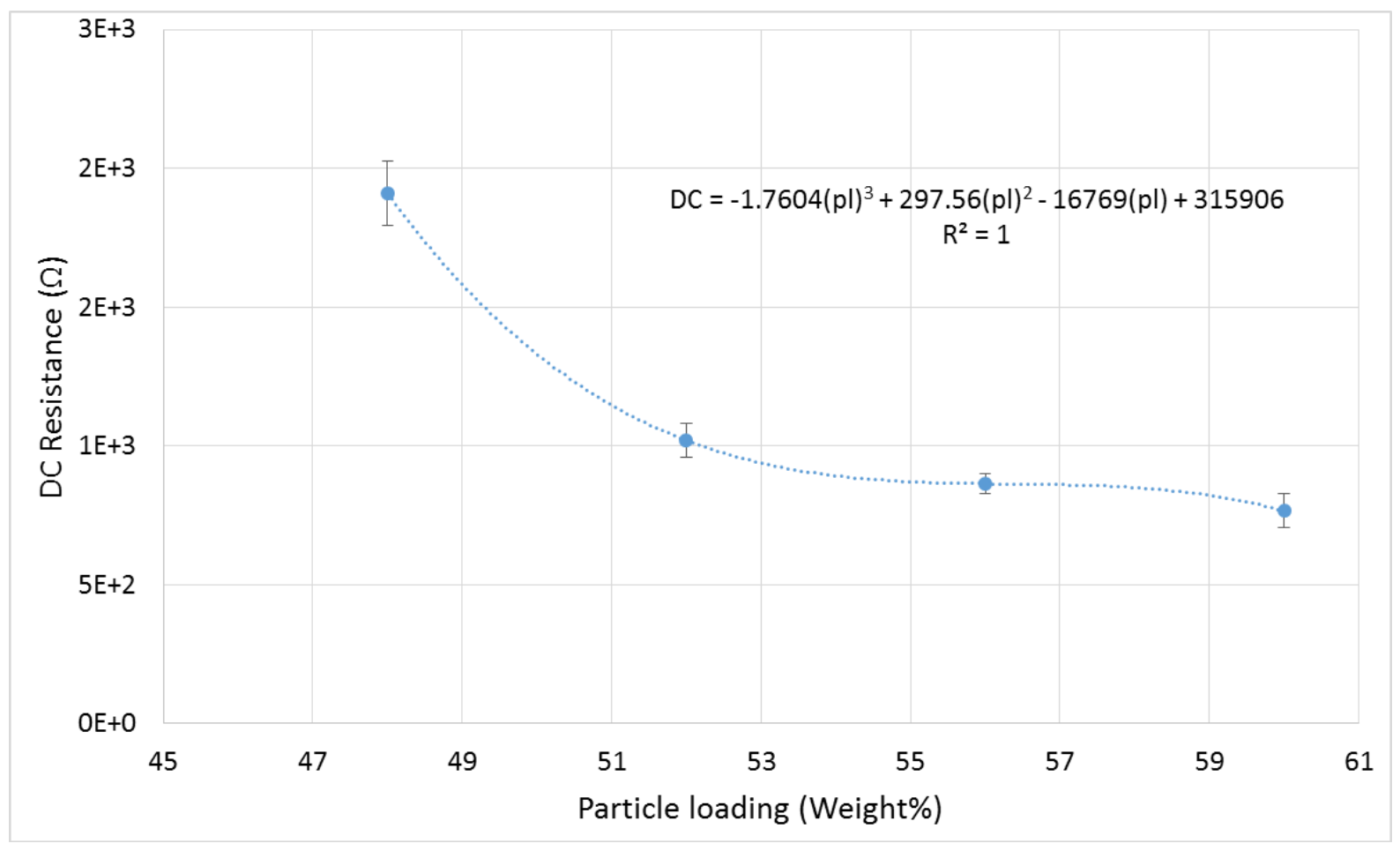

Lowering the particle loading causes the DC resistance measured after 40 minutes, $95^{\circ} \mathrm{C}$ curing to increase as shown in Figure 17. Also shown in the figure is the polynomial fit for final DC resistance where $\mathrm{pl}$ is particle loading. The fresh Paste $\mathrm{E}$ contains $60 \%$ of carbon conductive material. Decreasing the particle content by adding more solvent results in less conductive material for a given volume of paste, and with fewer current carrying particles the resistance will increase. 
Figure 18 The AC (TO) / DC (T40) ratio of different pastes, and Paste E for various curing temperature and particle loading. The blue bars show the average values and the error bars show standard deviation for 5 measurements in each test condition

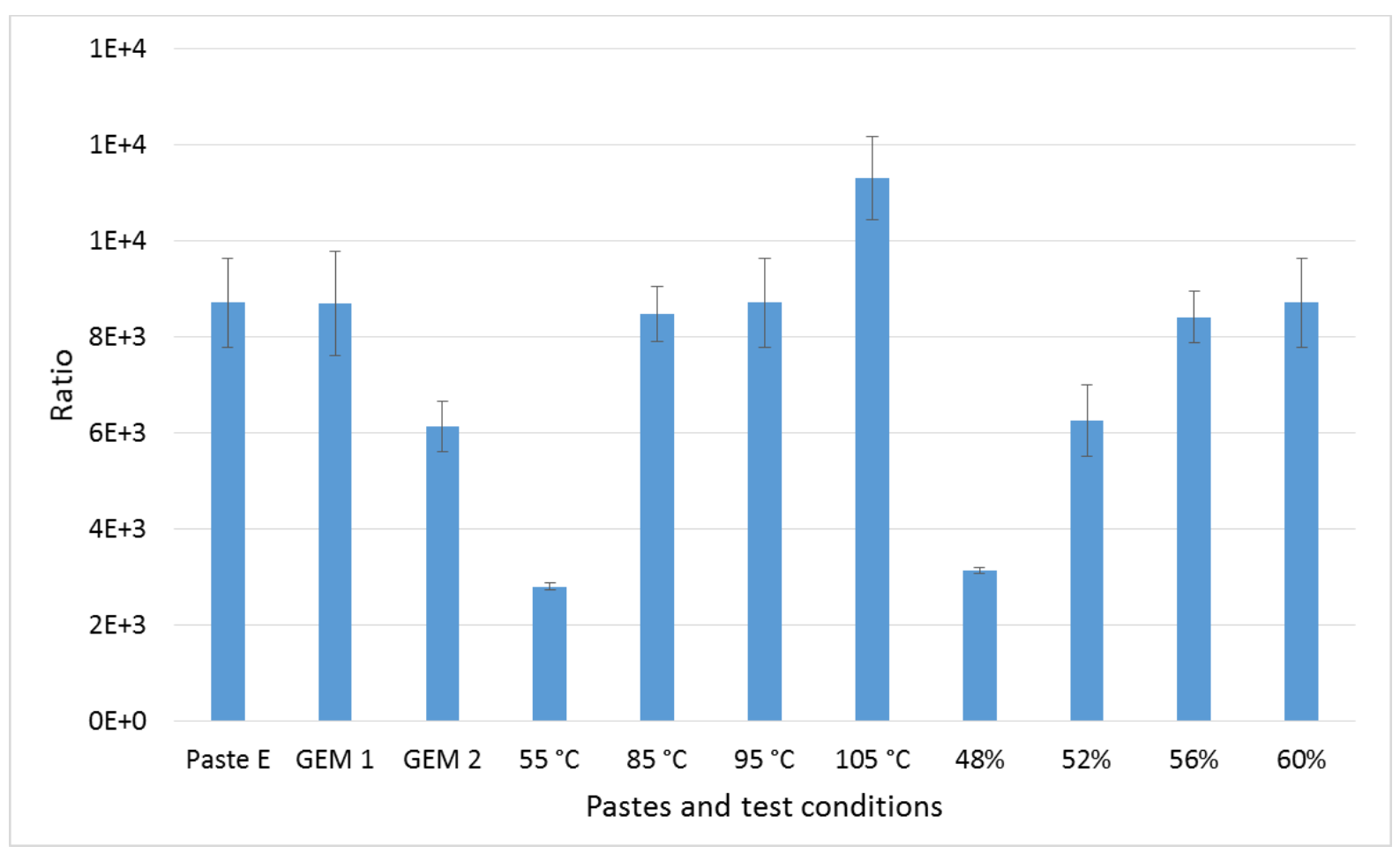

The prediction of printed electronics resistivity is made possible by identifying the ratio between the initial measurement and the final cured electrical properties. In this case we compare the initial impedance at $1 \mathrm{MHz}$ to the final $\mathrm{DC}$ resistance after cure. This ratio is shown for all 11 conditions investigated ( 5 samples tested for each condition) in Figure 18. Whilst each paste has a different ratio, the repeatability of the ratio value for a given paste is good as indicated by the standard deviations of $12 \%$ or less.

There is no significant difference between Paste E and GEM 1 AC (TO)/ DC (T40) ratio, however the ratio of GEM 2 is less compared to the two other pastes. This is due to the final DC resistance of GEM 2 being the highest among the three pastes. The GEM 2 DC high resistance could be due to the manufacturer's formulation.

There is an increasing trend with the $A C(T 0) / D C(T 40)$ ratio on samples cured at increasing temperatures. Figure 18 shows that the ratio is less on samples cured at $55^{\circ} \mathrm{C}$, then increases at 85 ${ }^{\circ} \mathrm{C}$ and $95^{\circ} \mathrm{C}$ and the highest recorded ratio is that of $105^{\circ} \mathrm{C}$. The ratio is less with low temperature curing because this will results in a higher resistance after curing at 40 minutes. As the cure temperature increases, the final cured resistance decreases.

Figure 18 shows that pastes with less particle loading produce a lower ratio between the initial and final resistance values. The paste with $48 \%$ particle loading has produced a lower ratio because the final resistance values are larger than that of the paste with the $60 \%$ loading. The increase in resistance is associated with the reduced amount of conductive particles in a given volume of the paste. 
The ratio as stated in Figure 18 for each corresponding paste, if divided by the initial AC Impedance at $1 \mathrm{MHz}$ will produce a predicted DC resistance of the printed structures. The same applies to the paste processed in various curing temperatures or different particle loading. If the final DC resistance value departs from the expected value then an investigation of the print process and materials is warranted.

An initial level of conductance is required for ohmic curing using DC current which typically necessitates a few minutes of initial air drying. However impedance measurements reported in this paper indicate that an AC current will flow more readily much earlier. Therefore if an AC current is used for ohmic curing, then the initial air drying can be reduced or eliminated.

\section{Conclusion}

An experimental method for measuring electrical properties of printed paste during cure has been presented. This experimental set-up is useful for understanding the change in electrical properties of printed structures during their cure cycle.

AC Impedance and DC Resistance measurement during cure provides insights into the development of printed electronics from liquid phase to solid phase. The early resistivity detection can potentially be used as quality assessment tool enabling product manufacturer to optimise their product quality and cost. We have used this set-up to investigate the benefits of impedance measurement during cure in order to get early indication of level of curing. The experiment on different curing temperatures shows the rate of evaporation of solvent through impedance measurement at $1 \mathrm{MHz}$. Meanwhile less particle loading will cause the final DC resistance at T40 to increase.

The components of the paste vehicle, in dispersing the paste particulate, cause the initial high impedance and DC resistance of an uncured paste film. Immediately after printing the DC resistance of the structure is $>100 \mathrm{M} \Omega$ whilst the impedance at $1 \mathrm{MHz}$ is over 4 orders of magnitude lower.

The initial measurement of the $\mathrm{AC}$ impedance of wet paste can give an early indication of the final cured resistivity for a particular paste whose cure cycle is already understood. Measurement of the initial uncured paste film impedance and final cured resistance gives a ratio that can be used to predict future print final resistivity from an initial uncured paste film impedance measurement. For the three carbon paste systems investigated, this ratio ranged from 766 to 1165 but was consistent within each paste system and curing temperature.

$A C$ impedance and DC resistance measurements during cure on conductive pastes with varying particle loadings show that the particle loading affects the rate of curing and the final resistance values. The percolation threshold is the beginning of a sudden reduction of $A C$ impedance and $D C$ resistance due to the establishment of sufficient particle to particle contact. Lowering the curing temperature delays the percolation threshold, while increasing the temperature will cause the paste to reach the percolation threshold quickly. Lower particle loading causes higher impedance and resistance values after 40 minutes of curing at $95^{\circ} \mathrm{C}$. The final resistance value for paste samples with lower particle loading is high, because there is less conductive material for a given volume of paste.

Curing temperatures for printed electronics influence both the speed of curing and the final impedance values. This is due to the solvent content increasing its rate of evaporation with the increase in curing temperature. The high curing temperature causes more solvent to evaporate, lowering the final resistance values of the printed structure. Lower curing temperature causes a delay in reaching the percolation threshold. Additionally, curing temperature affects the final resistance 
values obtained. Higher curing temperature evaporates more solvent forming increased particle to particle contact as compared to lower temperature post processing.

In summary, introduction of AC impedance measurement on printed conductive paste structures during cure is demonstrated as an effective tool in determining early indication of resistivity and measurement of degree of cure.

\section{References}

Baxter, L. K., 1997. Electrostatics. In: R. J. Herrick, ed. Capacitive Sensor : Design and Applications. New York: IEEE PRESS Marketing, p. 15.

Cummins, G. and Desmulliez, M.P.Y. (2012), "Inkjet printing of conductive materials: A review", Circuit World, Vol. 38, No. 4, pp. 193-213.

Derby, B. and Reis, N. (2003), "Inkjet Printing of Highly Loaded Particulate Suspensions", MRS Bulletin, Vol. 28, No. 11, pp. 815-818.

Evans, P.S.A., Harrey, P.M., Ramsey, B.J. and Harrison, D.J. (2001), "Lithographic film circuits - a review", Circuit World, Vol. 27, No. 3, pp.31-35.

E.H. Jewell, S.M. Hamblyn, T.C. Claypole, D.T. Gethin, (2013), "The impact of carbon content and mesh on the characteristics of screen printed conductive structures", Circuit World, Vol. 39, No. 1, pp. 13-21.

Familiant, Y.L., Corzine, K.A., Huang, J. and Belkhayat, M. (2005), “Ac Impedance Measurement Techniques", Proceedings of 2005 IEEE International Conference on Electrical Machines and Drives, pp. 18

Felba, J. (2011), "Inkjet Printed Electrically Conductive Structures for Microelectronics", Proceedings of $34^{\text {th }}$ International Spring Seminar on Electronics Technology, pp. 6-11.

Foyet, A., Wu, T.H., Kodentsov, A., van de Ven, L.,de With, G and van Benthem, R. (2009), "Impedance evaluation of permeability and corrosion of Al-2024 aluminum alloy coated with a chromate free primer", Progress in Organic Coatings, Volume 65, No. 2, pp. 257-262.

GREER, J.R. and STREET, R.A., 2007. Thermal cure effects on electrical performance of nanoparticle silver inks. Acta Materialia, 55(18), pp. 6345-6349.

INOUE, M. and SUGANUMA, K., 2006. Effect of curing conditions on the electrical properties of isotropic conductive adhesives composed of an epoxy-based binder. Soldering and Surface Mount Technology, 18(2), pp. 40-45.

Kim, Y., Kim, H. and Yoo, H.J. (2010), "Electrical Characterization of Screen-Printed Circuits on the Fabric", IEEE Transactions on Advanced Packaging, Vol. 33, No. 1, pp. 196-205. 
Lian, K., Li, R., Wang, H., Lu, Z. and Zhang, J. (2010), “ DC and AC analyses of a printed flexible memory device", Organic Electronics, Vol. 11, No. 6, pp. 1141-1144.

Mach, P. and Kolář, J. (2009), "Impedance of Adhesive Joints", Proceedings of $15^{\text {th }}$ International Symposium for Design and Technology of Electronics Packages, pp. 149-152.

MAKINEN, R., SILLANPAA, H., OSTMAN, K., PALUKURU, V., PYNTTARI, V., KANERVA, T., HAGBERG, J., LEPISTO, T., JANTUNEN, H., YANG, M., LAXTON, P.B., ARIMURA, H. and RONKKA, R., 2009. Wideband Electrical Characterization of printable nano-particle copper conductors, Microwave Conference, 2009. APMC 2009. Asia Pacific 2009, pp. 2455-2458.

Merilampi, S.L., Bjorninen, T., Vuorimäki, A., Ukkonen, L., Ruuskanen, P. and Sydanheimo, L. (2010), "The Effect of Conductive Ink Layer Thickness on the Functioning of Printed UHF RFID Antennas", Proceedings of the IEEE, Vol. 98, No. 9, pp. 1610-1619.

PEFFERKORN, A., 2012. Shrinkage characteristics of experimental polymer containing composites under controlled light curing modes. Polymers, 4(1), pp. 256-274.

PERELAER, J., DE LAAT, A.W.M., HENDRIKS, C.E. and SCHUBERT, U.S., 2008. Inkjet-printed silver tracks: Low temperature curing and thermal stability investigation. Journal of Materials Chemistry, 18(27), pp. 3209-3215.

Perelaer, J. et al., 2010. Printed electronics: the challenges involved in printing devices, interconnects, and contacts based on inorganic materials.. journal of Materials Chemistry, Volume 20, pp. p8446-8453.

PIRES-DE-SOUZA, F.C.P., DRUBI FILHO, B., CASEMIRO, L.A., GARCIA, L.F.R. and CONSANI, S., 2009. Polymerization shrinkage stress of composites photoactivated by different light sources. Brazilian dental journal, 20(4), pp. 319-324.

PYNTTÄRI, V.J., MAKINEN, R.M., PALUKURU, V.K., OSTMAN, K., SILLANPÄÄ, H.P., KANERVA, T., LEPISTO, T., HAGBERG, J. and JANTUNEN, H., 2010. Application of Wide-Band Material Characterization Methods to Printable Electronics. Electronics Packaging Manufacturing, IEEE Transactions on, 33(3), pp. 221-227.

Robertson, D.A, Wicker, R.B and Macdonald, E. (2012), "Ohmic Curing of Printed Silver Conductive Traces", Journal of Electronic Materials, Vol. 41 No. 9, pp. 2553-2566.

Salmerón, J. F., Torres, A.R., Banqueri, J., Carvajal, M.A. and Agudo, M. (2012), "Design and Characterization of Ink-jet and Screen Printed HF RFID Antennas", Proccedings of $4^{\text {th }}$ International EURASIP Workshop on RFID Technology, pp. 119-123.

SCHNEIDER, L.F.J., CAVALCANTE, L.M. and SILIKAS, N., 2010. Shrinkage stresses generated during resin-composite applications: A review. Journal of Dental Biomechanics, 1(1), pp. 1-14.

Yuan, X., Wang, H., Sun, J.C. and Zhang, J. (2007), "AC impedance technique in PEM fuel cell diagnosis-A review", International Journal of Hydrogen Energy, Vol. 32, No. 17, pp. 4365-4380. 
